\title{
Protective Effects of Curcumin on Cadmium-Induced Renal Injury in Young and Aged Rats
}

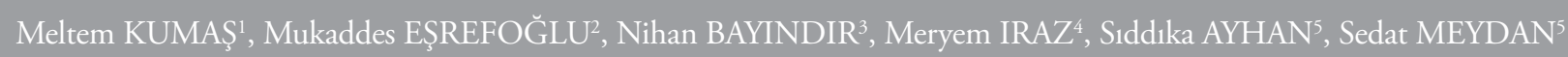

'Medical Laboratory, Bezmialem Vakıf University Health Care Vocational High School, İstanbul, Turkey

${ }^{2}$ Division of Basic Medical Sciences, Department of Histology and Embryology, Bezmialem Vakif University, İstanbul, Turkey

${ }^{3}$ Division of Basic Medical Sciences, Department of Medical Microbiology, Bezmialem Vakıf University, İstanbul, Turkey

${ }^{4}$ Division of Basic Medical Sciences, Department of Medical Biochemistry, Bezmialem Vakıf University, İstanbul, Turkey

${ }^{5}$ Division of Basic Medical Sciences, Department of Anatomy, Bezmialem Vakıf University, İstanbul, Turkey

\section{ABSTRACT}

Objective: We aimed to investigate the protective effects of curcumin $(\mathrm{Cr})$ against cadmium $(\mathrm{Cd})$ toxicity on the kidneys of both young and aged rats.

Methods: Forty-eight young and aged female Spraque-Dawley rats were divided into control, $\mathrm{Cd}, \mathrm{Cr}$, and $\mathrm{Cd}+\mathrm{Cr}$ groups. We investigated kidney damage using a histopathological scoring system and measured total antioxidant status (TAS) and total oxidant status (TOS) and interleukin-6 (IL-6), procalcitonin (PCT), and C-reactive protein (CRP) levels.

Results: Kidney tissues of $\mathrm{Cd}$ groups showed acute histopathological alterations. Cr improved Cd-induced histopathological changes $(\mathrm{p}<0.05)$. The highest mean TAS was recorded in both the Cr groups. The highest mean TOS was recorded only in the aged Cd group. Cr decreased IL-6 levels in both the $\mathrm{Cd}+\mathrm{Cr}$ groups $(\mathrm{p}<0.05)$. PCT levels in the $\mathrm{Cd}$ groups were higher than those in the control groups. Significance was detected only between the young $\mathrm{Cd}$ and control groups $(\mathrm{p}<0.05)$. PCT levels were reduced in both the $\mathrm{Cd}+\mathrm{Cr}$ groups $(p<0.05)$. CRP levels in the aged $\mathrm{Cd}$ group were higher than those in the other groups $(\mathrm{p}<0.05)$. Cr reduced CRP levels only in the aged $\mathrm{Cd}+\mathrm{Cr}$ group $(\mathrm{p}<0.05)$.

Conclusion: Our results suggest that $\mathrm{Cr}$ prevents $\mathrm{Cd}$-induced renal oxidative damage in both young and aged rats.

Keywords: Cadmium, curcumin, oxidative stress, interleukin, procalcitonin, C-reactive protein

\section{Introduction}

Cadmium (Cd) is a heavy metal that is one of the most toxic environmental pollutants (1). It was classified as a "group I carcinogen" by the International Agency for Research on Cancer. Humans and animals are exposed to Cd via contaminated soil, food, drinking water, and air as well as dust and smoke $(2,3)$. It is known that it causes time- or dosedependent toxicity in multiple organs of humans and animals. Cd causes oxidative tissue damage by accumulating mainly in the kidney, bone, brain, lung, and liver cells $(4,5)$. The effects of $\mathrm{Cd}$ on various cell types include chromatin condensation and damage to cell membranes, including the mitochondrial cristae membrane, resulting in an increase in their permeability (6). Cd exposure results in the impairment of the antioxidant defense system in the kidney and liver (7-9). As a matter of fact, the kidney is the most sensitive organ against $\mathrm{Cd}$. Thus, chronic $\mathrm{Cd}$ exposure through inhalation or oral ingestion leads to renal dysfunction (10). In particular, with aging, renal functions are impaired and the activity of antioxidant enzymes is decreased; thus, exposure to toxic agents is expected to be more injurious to organs in aged individuals.

Curcumin $(\mathrm{Cr})$ is the active component of turmeric (Curcuma longa) derived from rhizomes. Recent studies have reported various characteristic of $\mathrm{Cr}$, including antioxidant (11), anti-inflammatory (12), immunomodulatory, antiatherogenic, antiviral, and antifungal actions (13). In fact, $\mathrm{Cr}$ is a potent inhibitor of various reactive oxygen species. It exhibits protective effects against oxidative damage as a scavenger for free radicals and prevents lipid peroxidation. Cr binds to heavy metals such as $\mathrm{Cd}$ and lead and thus has a detoxificating effect against heavy metals (13). 
The aim of the current study was to compare the effects of $\mathrm{Cr}$ against $\mathrm{Cd}$-induced toxicity between the kidney tissues of young and aged rats.

\section{Materials and Methods}

\section{Experimental design}

Forty-eight young (age, 6 months) and aged (age, 16 months) female Spraque-Dawley rats weighing 250-300 g were randomly divided into the following groups: control group $(\mathrm{n}=6$, 10 days), Cd-treated group ( $\mathrm{Cd}, \mathrm{n}=6,10$ days), Cr-treated group $(\mathrm{Cr}, \mathrm{n}=6,10$ days), and cotreated group $(\mathrm{n}=6, \mathrm{Cd}$, 10 days $+\mathrm{Cr}, 10$ days). The animals were kept at $25^{\circ} \mathrm{C}$ under a 12-h light/12-h dark cycle, with free access to water and food. The rats received Cd (Merck Millipore, Billerica, Massachusetts, United States) intraperitoneally (ip.) at a dose of $0.5 \mathrm{mg} / \mathrm{kg} /$ day and Cr ip. at a dose of $50 \mathrm{mg} / \mathrm{kg} /$ day for 10 days. Cr (Sigma-Aldrich, St. Louis, Missouri, USA) was administered for 10 days after the administration of $\mathrm{Cd}$ in the cotreated group. At the end of the study, all rats were anesthetized with $80 \mathrm{mg} / \mathrm{kg}$ ketamine (Ketalar, Pfizer, Brooklyn, New York, USA) and $5 \mathrm{mg} / \mathrm{kg}$ xylazine $\mathrm{HCl}$ (Rompun, Bayer, Barmen, Germany), blood samples were collected from the heart, and later the kidneys were removed. The study procedure was approved by the Local Ethics Board for Animal Experiments, Bezmialem Vakıf University, İstanbul, Turkey (Decision No. 2013-231).

\section{Histopathology}

For histopathological analysis, kidney tissues were fixed in $10 \%$ neutral buffered formaldehyde and embedded in paraffin, $5 \mu \mathrm{m}$ longitudinal cross sections were obtained and stained with hematoxylin-eosin (H-E) and Masson's trichrome staining methods. Samples were examined and scored by a blinded observer using the Nikon Eclipse i5 light microscope with Nikon DS-Filc camera and the Nikon NIS Elements version 4.0 image analysis system (Nikon Instruments Inc., Tokyo, Japan).

Kidney damage was scored considering the tubular degeneration (including dilatation, squamation of the tubular epithelial cells, and necrosis), tubular vacuolization, glomerulosclerosis, hemorrhage, and interstitial fibrosis. Each data was scored as follows: 0: absent, 1: minimal, 2: moderate, and 3: severe with a maximum score of 15 .

\section{Biochemical analysis}

Blood samples derived from the heart were collected in jelled serum tubes. Serum was separated from the cells by centrifugation at $3,000 \times \mathrm{g}$ for 5 minutes. Plasma samples were stored at $-80^{\circ} \mathrm{C}$ until they were analyzed. Total antioxidant status (TAS) and total oxidant status (TOS) were determined by Erel's method (Rel Assay Diagnostics, Gaziantep, Turkey), which is automated and colorimetric. Erel's TOS method encompasses oxidizing ferrous ion to ferric ion in the presence of various oxidant species in an acidic medium and measuring ferric ion using xylenol orange. The results were explained in micromole $\mathrm{H}_{2} \mathrm{O}_{2}$ equivalent/ $\mathrm{L}\left(\mathrm{H}_{2} \mathrm{O}_{2}\right.$ equiv./L). Erel's TAS method is based on the bleaching of the characteristic color of a more stable 2.2'-azino-bis (3ethylbenz-thiazoline-6-sulfonic acid) radical cation by antioxidants. The results were expressed in millimole Trolox equivalent/L.

The percent ratio of the TOS value to the TAS value was defined as the oxidative stress index (OSI), which is an indicator of oxidative stress. The plasma OSI value was calculated using the following formula:

$$
\text { OSI }=\frac{\text { TOS }\left(\mu \mathrm{mol} \mathrm{H}_{2} \mathrm{O}_{2} \text { equivalent } / \mathrm{L}\right)}{\text { TAS }(\mathrm{mmol} \text { Trolox equivalent } / \mathrm{L}) \times 10}
$$

\section{Measurement of serum inflammatory factor levels}

The serum was instantly separated by centrifuging at 3000 $\mathrm{rpm}$ for 5 minutes and then stored at $-80^{\circ} \mathrm{C}$. Interleukin- 6 (IL-6) levels were determined using enzyme-linked immunosorbent assay (ELISA) kits (Rat IL-6 Platinum ELISA, eBioscience, Bender MedSystems GmbH, Vienna, Austria). The plasma levels of procalcitonin (PCT) were measured by using ELISA kits (Rat PCT Elisa Kit, Eastbio Pharm, Hangzhou Eastbiopharm Co., Hangzhou, China). The plasma levels of C-reactive protein (CRP) were quantified using ELISA kits (Rat CRP Elisa Kit, Assaypro, St. Charles, MO, USA) according to the manufacturer's instructions.

\section{Statistical analysis}

Statistical analyses were performed and bar charts were plotted using SPSS version 20.0 (IBM, New York, USA), MS Office Excel, and GraphPad Prism 6. The data about biochemical analysis and histopathological scores were statistically evaluated using the Mann-Whitney $U$ test for non-parametric data. In all the tests applied, the p significance degree (confidence interval) was evaluated at 95\%.

\section{Results}

\section{Oxidative stress parameters}

The highest mean TAS values were $0.97 \pm 0.45$ and $0.90 \pm 0.24$ in the young and aged Cr-treated groups, respectively. Mean TAS value in the young Cd group was lower than that in the control group; however, the mean TAS value in the $\mathrm{CD}+\mathrm{Cr}$ group was higher than that in the $\mathrm{Cd}$ group. In aged rats, the mean TAS values in the $\mathrm{Cd}$ and $\mathrm{Cd}+\mathrm{Cr}$ groups were nearly equal. In terms of the TAS values, no statistical significance was detected.

Total oxidant status values in the young groups did not show statistical differences at all; however, the mean TOS value in the Cd group was higher than that in the control group. Interestingly, the mean TOS values in the $\mathrm{Cr}$ and $\mathrm{Cd}+\mathrm{Cr}$ groups were higher than those in the $\mathrm{Cd}$ group.

In all the groups, the highest mean OSI values were detected to be $0.40 \pm 0.12$ and $0.39 \pm 0.10$ in the young and aged $\mathrm{Cd}$ groups, respectively. OSI values in the young and aged $\mathrm{Cd}$ 
group were higher than those in the control groups. $\mathrm{Cr}$ alone did not affect the OSI value in young rats; however, it reduced the OSI value in aged rats. Additionally, OSI values in the young and aged $\mathrm{Cd}+\mathrm{Cr}$ groups were lower than those in the Cd groups.

Mean blood TAS, TOS, and calculated OSI values obtained from all groups are presented in Table 1. Distribution of data regarding TAS (Figure 1), TOS (Figure 2), and OSI (Figure 3) in all groups is shown as bar charts.

\section{Inflammatory parameters}

It was observed that IL-6 levels were increased in the young and aged Cd groups when compared with the control groups, whereas these levels were decreased after $\mathrm{Cr}$ administration in both the young and aged $\mathrm{Cd}+\mathrm{Cr}$ groups. Significant differences were detected between the young and aged $\mathrm{Cd}$ and $\mathrm{Cd}+\mathrm{Cr}$ groups $(\mathrm{U}=0.000, \mathrm{p}=0.004$ and $\mathrm{U}=5.000, \mathrm{p}=0.003$, respectively).

The highest PCT levels were observed in the Cd groups. Cd affected mean PCT levels in young $(\mathrm{U}=0.000, \mathrm{p}=0.004)$ and aged rats and not in the control groups. PCT levels were reduced with the administration of $\mathrm{Cr}$ after that of $\mathrm{Cd}$ in both the young $(\mathrm{U}=0.300, \mathrm{p}=0.004)$ and aged groups.

The mean CRP level in the aged Cd group was found to be significantly higher than that in the control groups $(U=5.000$, $\mathrm{p}=0.037)$. CRP levels in both young $(\mathrm{U}=5.000, \mathrm{p}=0.041)$ and aged $\mathrm{Cd}+\mathrm{Cr}$ groups were lower than those in the $\mathrm{Cd}$ groups $(\mathrm{U}=5.000, \mathrm{p}=0.003)$.

Mean values of IL-6, PCT, and CRP of all groups are shown in Table 2. Bar charts of IL-6, PCT, and CRP are presented in Figures 4, 5, and 6, respectively.

\section{Histopathology of the kidney}

The mean histopathological score in the aged control group was higher than that in the young control group. Kidney tissues of both young and aged Cd groups showed some histopathological alterations, including tubular degeneration and vacuolization (Figure 7a), glomerular collapse, tubulointerstitial fibrosis (Figure 7b), mononuclear cell infiltration (Figure 7c), hemorrhage, edema, and necrosis (Figure 7d). Mean histopathological scores (MHSs) in the young and aged $\mathrm{Cd}$ groups were higher than those in the control groups ( $\mathrm{U}=0.000, \mathrm{p}=0.004$ and $\mathrm{U}=0.000, \mathrm{p}=0.004$, respectively). The histological appearance of the kidneys in the $\mathrm{Cr}$ groups was similar to that of the kidneys in the control groups in both young and aged rats (Figures $8 \mathrm{a}, \mathrm{b}$ ). It is obvious that in terms of MHSs, kidney tissues of the young groups were affected by $\mathrm{Cd}$ more severely than those of the aged groups (Figure 9).

$\mathrm{Cr}$ significantly improved $\mathrm{Cd}$-induced histopathological changes. In young and aged cotreated groups, minimal cellular changes such as tubular degeneration, mononuclear cell collapse, tubulointerstitial fibrosis, and hemorrhage were not obvious. Significant differences were detected between $\mathrm{Cd}$ and $\mathrm{Cr}$ young and aged groups in terms of MHSs $(\mathrm{U}=0.000$, $\mathrm{p}=0.004$ and $\mathrm{U}=0.000, \mathrm{p}=0.004$, respectively). Same results were valid for the comparison between $\mathrm{Cd}$ and $\mathrm{Cd}+\mathrm{Cr}$ groups ( $\mathrm{U}=0.000, \mathrm{p}=0.004$ and $\mathrm{U}=0.000, \mathrm{p}=0.004$, respectively).

Table 1. Mean serum total antioxidant status (TAS), total oxidant status (TOS), and oxidative stress index (OSI) values in all groups

\begin{tabular}{|c|c|c|c|}
\hline \multirow[b]{2}{*}{ Groups } & \multicolumn{3}{|c|}{ Mean \pm SD } \\
\hline & $\begin{array}{c}\text { TAS } \\
\text { (mmol Trolox } \\
\text { equ./L) }\end{array}$ & $\begin{array}{c}\text { TOS } \\
\text { ( } \mathrm{pmol} \mathrm{H2O2} \\
\text { equ./L) }\end{array}$ & $\begin{array}{c}\text { OSI } \\
\text { (TOS/ } \\
\text { TAS } \times 10)\end{array}$ \\
\hline Young Control & $0.78 \pm 0.22$ & $2.42 \pm 0.36$ & $0.33 \pm 0.10$ \\
\hline Aged Control & $0.86 \pm 0.28$ & $2.78 \pm 0.93$ & $0.33 \pm 0.05$ \\
\hline Young Cd & $0.72 \pm 0.23$ & $2.67 \pm 0.43$ & $0.40 \pm 0.12$ \\
\hline Aged Cd & $0.88 \pm 0.35$ & $3.21 \pm 0.79$ & $0.39 \pm 0.10$ \\
\hline Young $\mathrm{Cr}$ & $0.97 \pm 0.45$ & $3.04 \pm 0.86$ & $0.33 \pm 0.08$ \\
\hline Aged Cr & $0.90 \pm 0.24$ & $2.72 \pm 0.61$ & $0.30 \pm 0$. \\
\hline Young $\mathrm{Cd}+\mathrm{Cr}$ & $0.88 \pm 0.39$ & $2.99 \pm 0.95$ & $0.35 \pm 0.04$ \\
\hline Aged $\mathrm{Cd}+\mathrm{Cr}$ & $0.80 \pm 0.29$ & $2.82 \pm 0.90$ & $0.36 \pm 0.07$ \\
\hline
\end{tabular}

SD: standard deviation; mmol: millimolar; umol: micromolar; L: liter; equ: equivalent

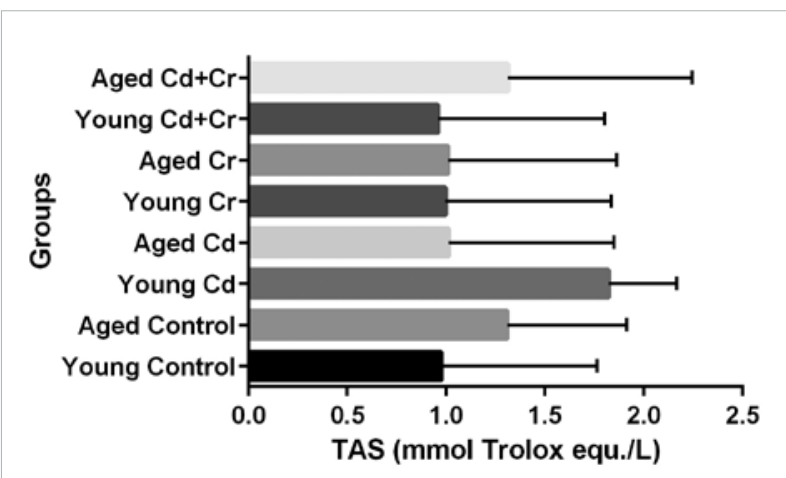

Figure 1. Bar chart of mean total antioxidant status (TAS) in all groups

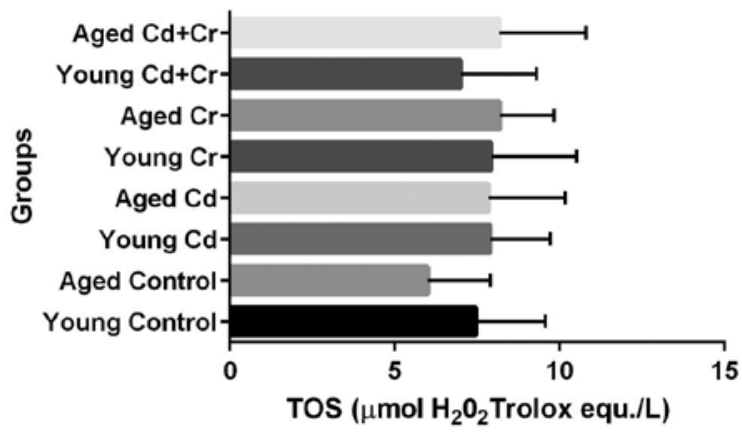

Figure 2. Bar chart of mean total oxidant status (TOS) in all groups 
Mean data of histopathological scores of kidney tissues in all groups are showed in Table 3. Bar chart of MHSs are presented in Figure 9.

\section{Discussion}

Acute $\mathrm{Cd}$ exposure through inhalation causes pulmonary edema and respiratory tract irritation, whereas chronic $\mathrm{Cd}$ exposure causes renal impairment, anemia, and bone defects (14). Chronic Cd exposure through inhalation or ingestion also causes renal dysfunction (10). The kidney is one of the

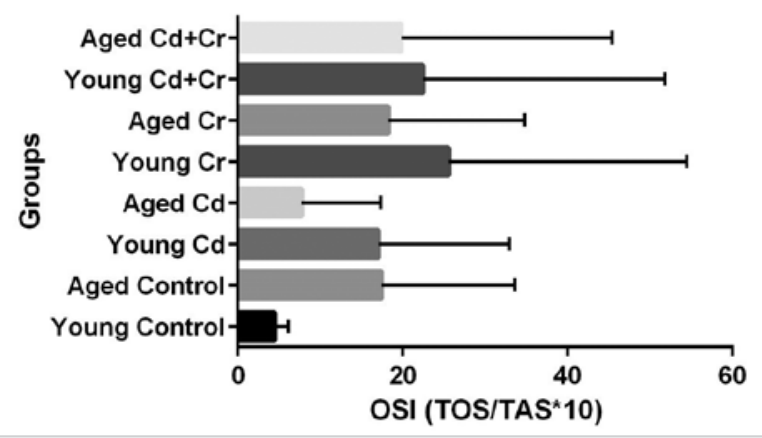

Figure 3. Bar chart of mean oxidative stress index (OSI) in all groups

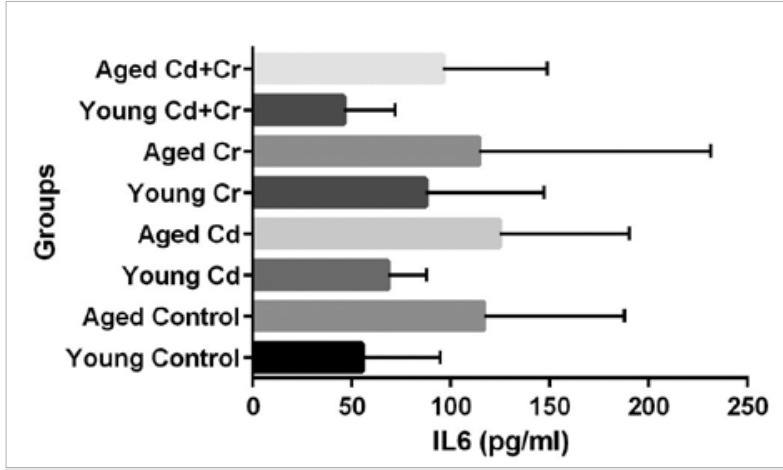

Figure 4. Bar chart of mean interleukin-6 (IL-6) levels in all groups

Table 2. Mean serum interleukin 6 (IL-6), procalcitonin $(\mathrm{PCT})$, and C-reactive protein (CRP) levels in all groups

\begin{tabular}{l|ccc|c}
\hline & \multicolumn{3}{c}{ Mean \pm SD } \\
\hline Groups & IL6 (pg/mL) & PCT (pg/mL) & CRP $(\mu \mathrm{g} / \mathrm{mL})$ \\
\hline Young Control & $55.40 \pm 39.24$ & $480.90 \pm 321.48$ & $0.38 \pm 0.23$ \\
\hline Aged Control & $106.07 \pm 74.70$ & $542.68 \pm 403.41$ & $0.38 \pm 0.37$ \\
\hline Young Cd & $66.96 \pm 20.57$ & $1750.20 \pm 250.38$ & $0.30 \pm 0.11$ \\
\hline Aged Cd & $121.93 \pm 69.70$ & $819.22 \pm 327.79$ & $0.89 \pm 0.39$ \\
Young Cr & $87.50 \pm 59.72$ & $681.10 \pm 342.87$ & $0.31 \pm 0.25$ \\
\hline Aged Cr & $115.47 \pm 106.22$ & $796.88 \pm 256.49$ & $0.37 \pm 0.32$ \\
\hline Young Cd+Cr & $53.96 \pm 29.59$ & $694.14 \pm 434.54$ & $0.20 \pm 0.13$ \\
\hline Aged Cd+Cr & $89.98 \pm 56.49$ & $645.41 \pm 241.83$ & $0.41 \pm 0.36$ \\
\hline SD: standard deviation; pg: picogram, $\mu$ g: microgram, ml: milliliter
\end{tabular}

most vulnerable organ against the toxic effects of $\mathrm{Cd}$ (15). Intoxication of $\mathrm{Cd}$ results in common transport defects of the proximal tubules $(9,16,17)$. In the present study, Cd caused severe renal damage in both the aged and young groups. Both

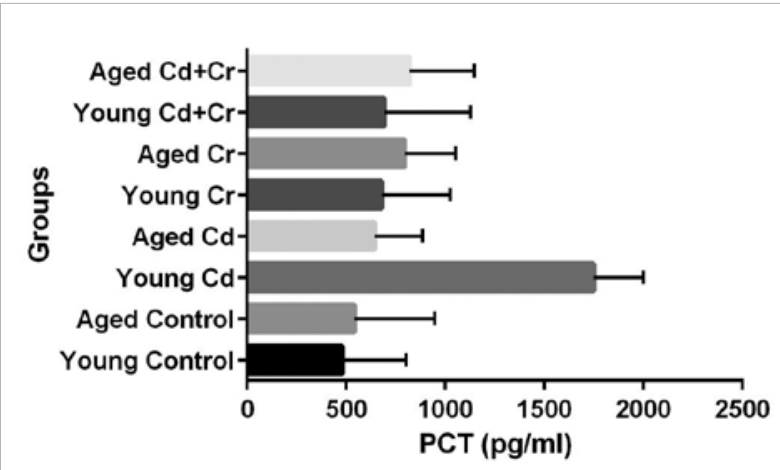

Figure 5. Bar chart of mean procalcitonin (PCT) levels in all groups

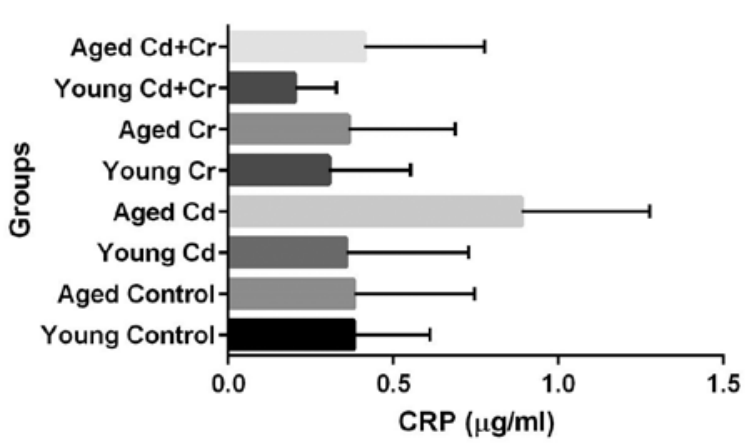

Figure 6. Bar chart of mean C-reactive protein (CRP) levels in all groups

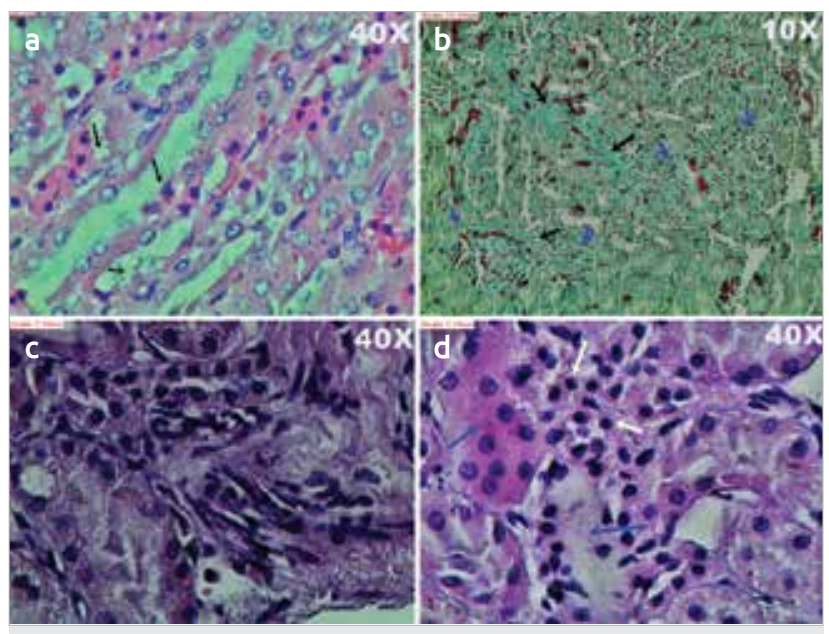

Figure 7. (a-d). Kidney sections from young and aged Cd groups. (a) Tubular degeneration in young groups (hematoxyline-eosin: H-E) (b) Glomerulosclerosis (blue arrows) and fibrosis (black arrows) in young groups (Masson's trichrome). (c) Mononuclear cell infiltration (H-E) in aged groups (d) Necrosis, edema, and mononuclear cell infiltration in aged groups (H-E) 
glomeruli and tubules were reported to be more sensitive against acute $\mathrm{Cd}$ toxicity than chronic toxicity (18). However, we observed prominent histopathological alterations within tubules and glomeruli following chronic $\mathrm{Cd}$ exposure. We detected tubular degeneration, necrosis, glomerular col-

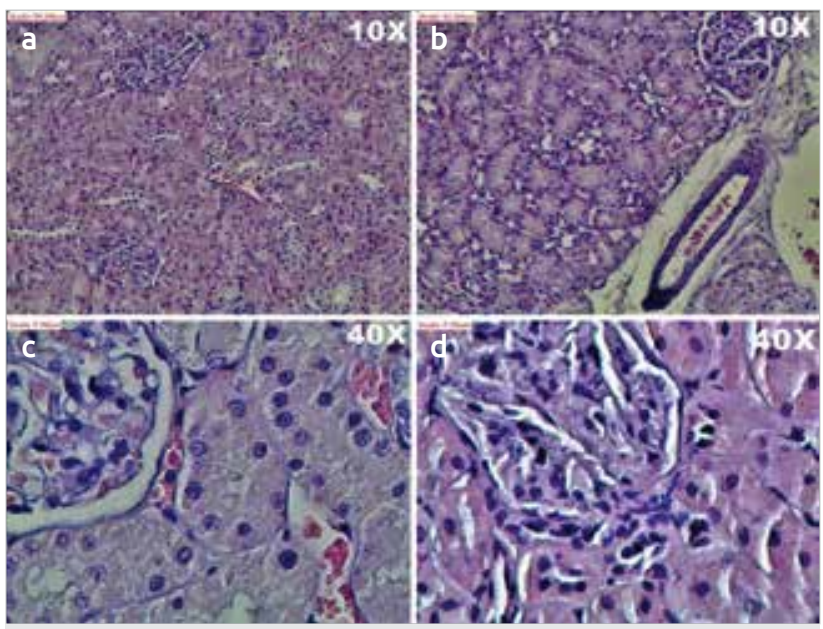

Figure 8. (a-d). Kidney sections from young and aged $\mathrm{Cr}$ groups. (c) Normal histological view of tubules and glomerulus from young $\mathrm{Cd}+\mathrm{Cr}$ group (H-E). (d) Minimal changes are shown in kidney sections from aged $\mathrm{Cd}+\mathrm{Cr}$ group (blue arrows: mononuclear cell infiltration around the glomerulus)

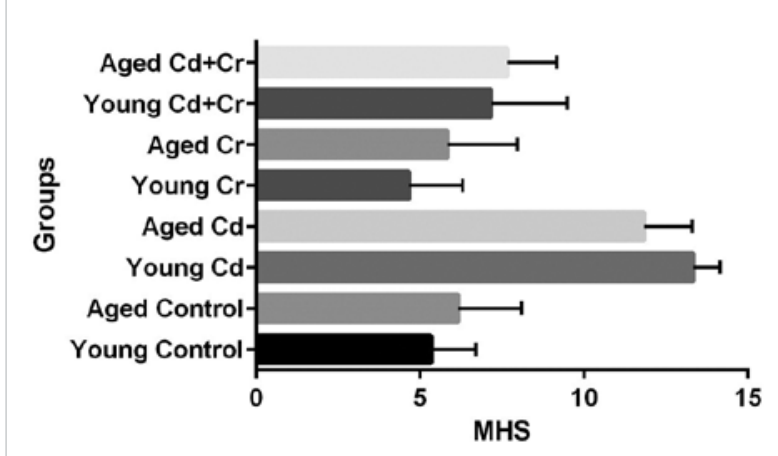

Figure 9. Bar chart of mean histopathological scores (MHSs) in all groups

Table 3. Mean histopathological scores (MHSs) of the kidney tissue in all groups

\section{Groups}

Young Control

Aged Control

Young $\mathrm{Cd}$

Aged Cd

Young $\mathrm{Cr}$

Aged $\mathrm{Cr}$

Young $\mathrm{Cd}+\mathrm{Cr}$

Aged $\mathrm{Cd}+\mathrm{Cr}$
MHSs ((Mean \pm SD)

$5.33 \pm 1.36$

$6.16 \pm 1.94$

$13.33 \pm 0.81$

$11.83 \pm 1.47$

$4.66 \pm 1.63$

$5.83 \pm 2.13$

$7.66 \pm 1.51$

$7.75 \pm 3.37$ lapse, mononuclear cell infiltration, hemorrhage, edema, and tubulointerstitial fibrosis. Surprisingly, although MHS in the aged control group was higher than that in the young control group, MHS in the aged Cd group was lower than that in the young $\mathrm{Cd}$ group. We suggest that aged renal tissues are more resistant to the damaging effects of toxic agents than young ones. We recently showed that liver tissues of the aged rats against chronic $\mathrm{Cd}$ exposure were also more resistant to the oxidant effects of $\mathrm{Cd}$ than those of the young rats (unpublished data). Additionally, in another study, we showed that renal tissue of aged rats exposed to ischemia and reperfusion was more resistant to the damaging effects of the process than that of young rats (unpublished data).

Interestingly, $\mathrm{Cd}$ administration caused higher damage in the young $\mathrm{Cd}$ group when compared with the aged $\mathrm{Cd}$ group. Although Cr significantly improved Cd-induced histopathological changes in the young and aged cotreated groups, $\mathrm{Cr}$ administration was more effective in young $\mathrm{Cd}+\mathrm{Cr}$ group than aged $\mathrm{Cd}+\mathrm{Cr}$ group. Significant differences were detected between the young and aged $\mathrm{Cd}$ and $\mathrm{Cr}$ groups in terms of MHSs $(p<0.005)$. Same results were valid for the comparison between the $\mathrm{Cd}$ and $\mathrm{Cd}+\mathrm{Cr}$ groups $(\mathrm{p}<0.005)$. Similarly, $\mathrm{Cr}$ has been shown to protect the renal structure in cisplatinexposed rats (19). Chronic Cr treatment also significantly attenuates both renal dysfunction and oxidative stress in diabetic rats $(20,21)$. Cr also prevented renal oxidative damage mediated by gentamicin; thus, it was suggested that it can be a potent protective agent (22). Similarly, in the present study, $\mathrm{Cr}$ treatment significantly improved the Cd-induced histological changes.

We detected that the mean TOS values in the aged control group were naturally higher than those in the young control group, and perhaps as a result of higher oxidative stress status, the mean TAS values in the aged control group were higher than those in the young control group. Higher antioxidant enzyme levels or activities should increase the tolerance of aged tissue against the hazardous toxic agents.

A previous study has reported oxidative stress in Cd-induced acute toxicity (21). Protection against these acute actions of $\mathrm{Cd}$ can be achieved through the antioxidant systems $(21,22)$. $\mathrm{Cr}$ has many beneficial features, including antioxidant and anti-inflammatory actions $(11,12)$. We tried to investigate antioxidant and anti-inflammatory efficacy of $\mathrm{Cr}$ against renal toxicity in our study. Thus, $\mathrm{Cr}$ administration alone affected the mean serum TAS value in both the young and aged rats versus the controls. Cr also affected the TAS value in $\mathrm{Cd}$-administered young rats but not that in aged rats. On the other hand, OSI (mean TOS/mean TAS $\times 10$ ) in both the young and aged $\mathrm{Cd}$ groups were higher than those in the $\mathrm{Cd}+\mathrm{Cr}$ groups. Because higher values of OSI represent higher oxidative stress status, we suggest that $\mathrm{Cr}$ inhibits oxidative stress.

Because acute $\mathrm{Cd}$ exposure causes severe inflammation, it activates inflammation markers depending on the severity 
of stress within the cells. IL-6 is a proinflammatory cytokine that plays a critical role in the human defense system (23-25). Many toxic agents and pathological conditions, such as bacterial and viral infections, trauma, and autoimmune diseases, induce production or affect the function of cytokines, including IL-6 (26). In the present study, although extensive inflammation was not detected in renal tissue of the groups, IL-6 levels in the young and aged $\mathrm{Cd}$ groups were increased probably as a result of the inflammation of other affected organs, including the liver, heart, pancreas, etc. On the other hand, $\mathrm{Cr}$ administration reduced IL- 6 levels of young $(\mathrm{p}=0.004)$ and aged $(\mathrm{p}=0.003)$ rats of the $\mathrm{Cd}$ groups.

Cytokines synthetized by neutrophils and macrophages stimulate the production of acute-phase proteins, including Creactive protein (CRP) and procalcitonin (PCT). Procalcitonin, a precursor of the hormone calcitonin, is synthetized by $\mathrm{C}$ cells of the thyroid gland and neuroendocrine cells of the lungs, pancreas, intestine, and liver during infection and inflammation $(27,28)$. CRP is synthesized by the hepatocytes. CRP levels in serum increase in response to IL-6 during infection and inflammation (29). Cr has considerable inhibitory effects on the production of TNF- $\alpha$ (30). It was stated that $\mathrm{Cr}$ administration reduced serum levels of TNF- $\alpha$ and IL-6 in cisplatin-exposed rats $(19,31)$. Cr had protective effects against liver fibrogenesis via reducing TNF- $\alpha$ and IL- 6 levels in the liver and serum (32-35).

C-reactive protein is a marker, which appears during the late phase of infection, whereas IL- 6 and PCT are affected in the early phase (36-38). In the present study, increased PCT levels of Cd-administered young $(\mathrm{p}=0.004)$ and aged $(\mathrm{p}=0.004)$ rats were reduced by $\mathrm{Cr}$ administration. On the other hand, mean CRP levels in the young Cd group were reduced probably as a result of liver failure. As we mentioned before, CRP is mainly produced by the hepatocytes. As a matter of fact when we examined the liver section of $\mathrm{Cd}$-administered young rats, we observed extensive necrosis (unpublished data). In aged rats, increased levels of CRP were reduced by $\mathrm{Cr}$ administration presenting its anti-inflammatory function $(\mathrm{p}=0.003)$. It was known that $\mathrm{Cr}$ exhibits anti-inflammatory activity, so it was determined to levels of pro-inflamatory markers.

\section{Conclusion}

We suggest that inflammation and oxidative damage induced by $\mathrm{Cd}$ is inhibited by $\mathrm{Cr}$. Cr prevents $\mathrm{Cd}$-induced renal oxidative damage in both young and aged rats and should be considered as a therapeutic agent against toxic oxidative stress.

Ethics Committee Approval: Ethics committee approval was received for this study from Bezmiâlem Vakıf University Ethics Committee of Experimantal Animal.

Informed Consent: Not required in this study.

Peer-review: Externally peer-reviewed.
Author Contributions: Concept - M.E., M.K., N.B., Design - M.K., M.E; Supervision - M.E., S.M., M.I.; Data Collection and/or Processing - M.K., N.B., S.A., M.I.; Analysis and/or Interpretation - M.E., M.K., M.I., S.M., N.B. , S.A; Literature Review - M.K., N.B.; Writing - M.K., M.E.; Critical Review - M.E.

Conflict of Interest: No conflict of interest was declared by the authors.

Financial Disclosure: The authors declared that this study has received no financial support.

\section{References}

1. Tchounwou PB, Yedjou CG, Patlolla AK, Sutton DJ. Heavy metals toxicity and the environment. Mol Cli Environ Toxicol 2012; 101: 133-6. [CrossRef]

2. Elinder CG. Biological monitoring of cadmium. In: Biological monitoring of exposure to chemical metals. New York: John Wiley and Sons; 1991.p.197-207.

3. Jarup L. Hazards of heavy metal contamination. Br Med Bull 2003; 68: 167-82. [CrossRef]

4. Ashour TH. Preventative effects of caffeic acid phenyl ester on cadmium intoxication induced hematological and blood coagulation disturbances and hepatorenal damage in rats. Hematol 2014; 1-7.

5. Satarug S, Garrett SH, Sens MA, Sens DA. Cadmium, environmental exposure and health outcomes. Environ Health Perspect 2010; 118: 182-90. [CrossRef]

6. Fasanya-Odewumi C, Latinwo LM, Ikediobi C. The genotoxicity and cytotoxicity of dermally-administered cadmium: Effects of dermal cadmium administration. Int J Mol Med 1998; 1: 1001-6. [CrossRef]

7. Rikans LE, Yamano T. Mechanisms of cadmium-mediated acute hepatotoxicity. J Biochem Mol Toxicol 2000; 14: 110-7. [CrossRef]

8. Stohs SJ, Bagchi D, Hassoun E, Bagchi M. Oxidative mechanisms in the toxicity of chromium and cadmium ions. J Environ Pathol Toxicol Oncol 2000; 20: 77-88.

9. Yurekli M, Esrefoglu M, Doğru MI, Doğru A, Gul M, Whidden M. Adrenomedullin reduces antioxidant defense system and enhances kidney tissue damage in cadmium and lead exposed rats. Environ Toxicol 2009; 24: 279-86. [CrossRef]

10. Liu J, Qu W, Kadiiska MB. Role of oxidative stress in cadmium toxicity and carcinogenesis. Toxicol Appl Pharm 2009; 238: 209-14. [CrossRef]

11. Fowler BA. Monitoring of human populations for early markers of cadmium toxicity: a review. Toxicol Appl Pharmacol 2009; 238: 294-300. [CrossRef]

12. Kunchandy E, Rao MNA. Oxygen radical scavenging of curcumin. Int Journal Pharm 1990; 58: 237-40. [CrossRef]

13. Akram M, Ahmed A. Curcuma longa and curcumin: A Review article. Rom J Biol-Plant Biol 2010; 55: 65-70.

14. Friberg L, Nordberg GF, Vouk VB, eds. Handbook of the toxicology of metals. Vol. II. Amsterdam: Elsevier; 1986.p.130-84.

15. Yasuda M, Miwa A, Kitagawa M. Morphometric studies of renal lesion in Itai-Itai disease: Chronic cadmium nephropathy. Nephron 1995; 69: 14-19. [CrossRef]

16. Brzoska MM, Kaminski M, Supernak-Bobko D. Changes in the structure and function of the kidney of rats chronically exposed to Cd. I. Biochemical and histopathological studies. Arch Toxicol 2003; 77: 34452. [CrossRef]

17. Buchet JP, Lauwerys R, Roels H, Bernard A, Bruaux P, Claeys F, et al. Renal effects of cadmium body burden of the general population. Lancet 1990; 336: 699-702. [CrossRef]

18. Ashraf M, Kamar MS. Acute effect of cadmium treatment on the kidney of rats; biochemical and ultrastructural studies. Pakistan J Biol Sci 2007; 10: 3497-506. [CrossRef]

19. Kuhad A, Pilkhwal S, Sharma S, Tirkey N, Chopra K. Effect of curcumin on inflammation and oxidative stress in cisplatin-induced experimental nephrotoxicity. J Agric Food Chem 2007; 55: 10150-155. [CrossRef] 
20. Sharma S, Kulkarni SK, Chapra K. Curcumin, the active principle of turmeric (Curcuma longa), ameliorates diabetic nephropathy in rats. Clin Exp Pharmacol P 2006; 33: 940-45. [CrossRef]

21. Babu PS, Sriniyasan K. Amelioration of renal lesions associated with diabetes by dietary curcumin in streptozotocin diabetic rats. Mol Cell Biochem 1998; 181: 87-96. [CrossRef]

22. Farombo EO, Ekor M. Curcumin attenuates gentamicin-induced renal oxidative damage in rats. Food Chem Toxicol 2006; 44: 1443-48. [CrossRef]

23. Sarkar S, Yadav P, Trivedi R, Bansal AK, Bhatnagar D. Cadmium induced lipid peroxidation and status of antioxidant system in rats' tissues. J Trace Elem Med Biol 1995; 9: 144-9. [CrossRef]

24. Rana SVS, Verma S. Protective effects of GSH, vitamin E and selenium on lipid peroxidation in cadmium-fed rats. Biol Trace Elem Res 1996; 51: 161-8. [CrossRef]

25. Hirano T. Interleukin-6 and its receptor: ten years later. Int Rev Immunol 1998; 16: 249-84. [CrossRef]

26. Akramiene D, Kondrotas A, Didziapetriene J, Kevelaitis E. Effects of beta-glucans on the immune system. Medicina (Kaunas) 2007; 43: 597-606.

27. Yücesoy B, Turhan A, Ure M, Imir T, Karakaya A. Effects of occupational lead and cadmium exposure on some immunoregulatory cytokine levels in man. Toxicol 1997; 123: 143-7. [CrossRef]

28. Taga T, Kishimoto T. Gp130 and the interleukin- 6 family of cytokines. Annu Rev Immunol 1997; 15: 797-819. [CrossRef]

29. Qu J, Lü X, Liu Y, Wang X. Evaluation of procalcitonin, C-reactive protein, interleukin-6 \& serum amyloid A as diagnostic biomarkers of bacterial infection in febrile patients. Indian J Med Res 2015; 141:31521. [CrossRef]
30. Nijsten MW, Olinga P. Procalcitonin behaves as a fast responding acute phase protein in vivo and in vitro. Crit Care Med 2000; 28: 458-61. [CrossRef]

31. Simon L, Gauvin F, Amre DK, Saint-Louis P, Lacroix J. Serum procalcitonin and C-reactive protein levels as markers of bacterial infection: A systematic review and meta-analysis. Clin Infect Dis 2004; 39: 206-17. [CrossRef]

32. Abe $\mathrm{Y}$, Hashimoto $\mathrm{S}$, Horie T. Curcumin inhibition of inflammatory cytokine production by human peripheral blood monocytes and alveolar macrophages. Pharmacol Res 1999; 39: 41-7. [CrossRef]

33. Mahfouz MKM. Curcumin improves insulin sensitivity and ameliorates serum proinflammatory cytokines levels in diabetes rat model irrespective of type of diabetes. J Am Sci 2011; 7: 794-9.

34. Fu Y, Zheng S, Lin J, Ryerse J, Chen A. Curcumin protects the rat liver from CCl4-caused injury and fibrogenesis by attenuating oxidative stress and suppressing inflammation. Mol Pharmacol 2008; 73: 399-409. [CrossRef]

35. Kataranovski M, Kataranovski D, Savic D, Jovcic G, Bogdanovic Z, Jovanovic T. Granulocyte and plasma cytokine activity in acute cadmium intoxication in rats. Physiol Res 1998; 47: 453-61.

36. Krocova Z, Macela A, Kroca M, Hernychova L. The immunomodulatory effect(s) of lead and cadmium on the cells of immune system in vitro. Toxicol In Vitro 2000; 14: 33-40. [CrossRef]

37. Alghasham A, Salem TA, Meki AM. Effect of cadmium-polluted water on plasma levels of tumor necrosis factor-a, interleukin- 6 and oxidative status biomarkers in rats: Protective effect of curcumin. Food Chem Toxicol 2013; 59: 160-4. [CrossRef]

38. Iraz M, Iraz M, Eşrefoğlu M, Aydın MS. Protective effect of $\beta$-glucan on acute lung injury induced by lipopolysaccharide in rats. Turk J Med Sci 2015; 45: 261-7. [CrossRef] 